\title{
Video Analysis in Golf Coaching: An Insider Perspective
}

Fanie Roos

\author{
North-West University (Vaal Triangle Campus), Faculty of Economic Sciences and Information Technology \\ Jhalukpreya Surujlal
}

North-West University (Vaal Triangle Campus), Faculty of Economic Sciences and Information Technology

\section{Doi:10.5901/mjss.2014.v5n21p399}

\section{Abstract}

Golf has evolved from a recreational pursuit to a professional sport, which attracts huge sponsorships and endorsements. With this development, greater demands have been placed on golf coaches to produce golfers with high levels of skills and competence. The technology used in golf coaching has also evolved with video analysis becoming an integral part of golf coaching. The purpose of this study was to elicit golf coaches' perspectives on golf coaching. A qualitative research approach using semi-structured interviews was used to collect data from a purposive sample of eight ( $n=8)$ golf coaches. Interviews were recorded and transcribed verbatim. Arising from an in-depth literature review, an interview schedule was developed to collect data on the following research issues associated with using video analysis in golf coaching: a) positive experiences, b) negative experiences, c) player development, d) attitude towards video analysis, e) barriers and constraints to using video analysis, f) focus of video analysis, and g) alternatives to video analysis. The data were content-analysed to reduce it to meaningful information units. The findings of the study revealed that the positive aspects outnumbered the negative aspects associated with the use of video analysis in golf coaching. Among the positive aspects were improved stance, balance and swing, while the negative aspects were mainly concerned with the high cost of the technology. Given the many positive aspects associated with using video analysis in golf coaching, and the fact that coaches continuously strive to get the best performance from their athletes, the use of video analysis in golf coaching appears to be a positive step towards achieving this goal.

Keywords: video analysis; golf coaching; swing; technology; stance

\section{Introduction}

The advent of advanced technology has created the opportunity for sport coaches to access accurate information and select appropriate tools or equipment to incorporate in their training programmes. Van Staden (2014) argues that the increased improvement in sport is not as a result of human beings evolving faster than other mammals, but as a result of more accurate information on one's fingertips to make better choices. Assessment in sport may be invasive or noninvasive, with the latter increasingly being used due to advanced technology. The use of invasive assessments is often very expensive and frequently hinders the training program of athletes. Technology also allows coaches to make better training choices in terms of techniques, intensity and frequency.

The game of golf has evolved from a recreational pursuit to a professional sport that attracts lucrative endorsement opportunities for promising golfers, and high sponsorship for national and international golf tournaments. Accompanying this evolution were large-scale changes in the approach to golf, the equipment used in golf and golf coaching. While most individuals still play golf for recreation, the game has produced highly paid professionals such as Tiger Woods, Gary Player, Ernie Els and Jack Nicklaus, to name a few, who made a career of the sport. In the early days, the sport was played with wooden clubs and required little or no coaching. With the passage of time, the attractive and increasing prize money for tournaments began capturing the attention of players of both sexes. With higher participation and spectatorship, competition soared. For players to enter and remain in competitions/tournaments, they needed the requisite skill and competence. Hence, it became necessary for them to receive professional coaching. Golf coaching does not just involve learning technical skills. In addition to technical skills, players need to have an awareness of their ability to play the sport and a positive mental approach to the sport (Cromack, 2011). The game was played initially with wooden sticks. However, the introduction of the steel shaft was not only cost-effective but also provided more comfort. Players were able to choose a specific shaft - medium, regular or stiff to match their swing. Graphite shafts, especially, have become very popular, as players with slow swing speeds could now get more distance from the same swing. 
Lane (2007) comments, that when golf was initially played in the $13^{\text {th }}$ century, it was played by teams of players who would alternate hitting the ball. The only strategy and technique that was required was devising the most efficient means of hitting the ball into an area from which the opposing team would find it difficult to play. In the next few centuries, the production of golf balls was both laborious and expensive (Lane, 2007). Therefore, the playing of golf was restricted to small areas, and individuals learnt from imitating good players. In the early 1900s, legitimate tournaments such as the British Open and the US Open emerged as attractive tournaments to play in. The difficulty level of the tournaments increased with the introduction of different golf courses and different equipment. The real boom in golf began in the 1950s when young amateurs forsook their careers to pursue golf because of the high prize money and endorsement income. Golf has since found a home in print and broadcast media, which provided instruction and marketed the sport. Golf schools and offerings of golf courses at institutions of higher education started mushrooming in the 1980s. It was during this time that specialised instruction in the sport emerged. Video analysis of the golf swing was one of these.

\section{Video Analysis in Golf Coaching}

Unlike many sports where coaching is a face-to-face interaction, social networks and improved technology have made it possible for golfers to get coaching tips at times which are most convenient to them. For example, social networks and video analysis, as methods of golf coaching to analyse a golf swing, can be done across continents.

Regardless of the sport, proper feedback from coaches is the most important thing. A golf coach is able to get improved attention, response and performance from students if the students have visual images of what they are doing wrong. Video analysis using V1 Pro, for example, as a coaching aid works wonders and a much quicker improvement in players can be observed, regardless of their age. V1 Pro is a versatile programme, which is able to record videos, has user-friendly tools, can be played back in slow motion, and provides multiple views of students' movements. Video clips of students' swings and stances can be compared with those of professional golfers. An important positive aspect of the V1 Pro is that information can be emailed to students, who can download the information and use it at their leisure. Another programme that professional golf coaches use is Powerchalk. This is similar to V1 Pro and also provides coaches with accurate feedback, as well as many model swings from professional players. This technology, however, is less user-friendly than V1 Pro. Many of the world's top golf coaches have included video analysis in their coaching, for example Butch Harmon, one of Americas greatest golf teachers for 12-straight years, as nominated by his peers (Harmon, 2014), uses advanced video equipment to help his players achieve their potential in the sport. Other renowned coaches such as Sean Foley (coach of 16 times major champion Tiger Woods), and Jim Mclean (the Jim McLean Golf Centre-Texas is regarded as the one of the leading golf schools in the United States), also use video analysis extensively to get the best out of their players (McLean, 2014). Video analysis is a technique used to obtain information about moving objects from video (Wikipedia, 2014). Unlike in the past when coaches made judgements based on their own experience, knowledge and subjectivity, video analysis accurately measures angle movements to the spine, arm flex, and general posture positions, thereby removing the guesswork associated with traditional coaching methods (Anon, 2008). Video analysis involves the use of high-speed video cameras, biomechanic vests, force plates, radar tracking units and devices using infra-red and ultrasound technology to accurately monitor and record the movement of players. Instead of providing a one-dimensional feedback, the biomechanics included in video analysis provide multiple dimensions of movement. This is done through attaching sensors, which are usually in different places of a vest or waistcoat that allow for the detection and analysis of movements. Different video analysis systems may include other components, for example the force plate or balance plate, which provides information on where a player's weight is during a swing sequence. Depending on the coaching needs and the available resources (inter alia financial), video analysis provides many possibilities.

There are many benefits associated with the use of video analysis; among these are reduced injuries (McCarron, 2013). Video analysis makes it possible to detect weaknesses in respect of the golf swing, which may lead to future injury; such injury can be corrected or prevented at an early stage. This type of analysis is hardly possible using traditional coaching methods. Most golf injuries arise through incorrect techniques (Johnson, 2011) because amateurs and less competent players try to imitate professionals. Every good golf swing analysis system comes with an extensive library for both male and female professionals to use as swing templates (Anon, 2008). With such information, athletes can discover weaknesses in their own techniques, and easily correct their technique; thereby, also improving their performance. Another benefit of video analysis is scouting at sports institutions. Universities and schools have developed scouting as one of the most important aspects in their success, using video analysis, a coach can analyse an athlete to the extent that he/she fits perfectly into what the coach is looking for. By using video analysis, a coach can present concrete evidence of why the player will be valuable to the team. It will prevent making expensive recruitment and selection decisions on observations with the naked eye. 
Another important benefit is that feedback need not necessarily be face-to-face with the athlete. The feedback can be emailed to the athlete who can download the information and start working on his/her technique at a time most suitable to him/her.

However, there are constraints associated with the use of video analysis in golf coaching; one of the major drawbacks is the high cost. Video equipment is very expensive, and technology is advancing so rapidly that a newly purchased expensive system may become obsolete in a short time before even realising a fair return on its investment. Video analysis is also a time-consuming process for the coach, because it takes up many hours outside the normal coaching sessions to analyse all the data and provide detailed feedback to the players. The video analysis would be meaningless if the data is not applied correctly to improving the performance of the athlete. Very often coaches using technology can become too technical and confuse players or inhibit their natural ability. Thus, a coach needs to know when to step away from the technology. If the technology is used incorrectly, it can result in incorrect data being captured. For example, if the video equipment is not directly behind the player, the coach will not see the correct angle and alignment needed to provide proper feedback.

\section{Purpose of the Study}

The purpose of the study was to elicit insider perspectives on video analysis in golf coaching. Insiders, in the context of this study, are professional golf coaches who use video analysis in their coaching.

\section{Methodology}

A comprehensive literature review of video analysis was conducted. Given the uniqueness of the phenomenon being researched, the authors deemed a qualitative research approach as appropriate for the study. Patton (2002) posits that this approach provides the opportunity to explore the real-life world of respondents, and obtain an insider perspective of the phenomenon being researched. It evokes meaningful responses that are applicable to the experiences of the respondent. In this approach, data are collected in the respondent's own words, rather than limiting them to select from fixed responses required in a quantitative approach (Sooful, Surujlal \& Dhurup, 2010). Semi-structured face-to-face interviews were conducted with five professional golf coaches. Furthermore, an additional three telephonic interviews were conducted with those professional golf coaches who were not within geographical access to the researchers. All respondents were recruited through purposive sampling. Dane (1990) argues that purposive sampling allows the researcher to deliberate on people or events, which have good grounds in what they believe, that are critical for the study. Professional golf coaches who used video analysis for at least one year on a regular basis to provide feedback to their athletes were approached, and requested to participate in the study. The principal researcher, who himself is a professional golf coach and affiliated to the Professional Golfers' Association (PGA), accessed the contact details of potential participants from the database of affiliated coaches. Of those coaches who used video analysis in their coaching, eight accepted the request to participate in the study.

\subsection{Instrument and procedures}

The literature review contributed to the development of an interview schedule. Two researchers with experience in qualitative research and knowledge of the game of golf assessed the content of the interview schedule. Based on their recommendations, modifications were made to the interview schedule. A pilot test of the instrument was conducted to determine the most logical order of questions, as well as the approximate duration of the interview. The following research issues were explored in the study: a) positive experiences, b) negative experiences, c) player development, $d$ ) attitude towards video analysis, e) barriers and constraints to using video analysis, f) focus of video analysis, and $g$ ) alternatives to video analysis.

The face-to-face interviews were of approximately 25 minutes duration, while the telephonic interviews were of approximately 15 minutes duration. In both instances, the interviews were recorded and transcribed verbatim. A cellular phone was used to record the telephonic interviews, which were subsequently downloaded on a computer. Probes were used to follow up on issues that needed clarity. Core ethical issues such as respect, honesty, confidentiality and anonymity were adhered to during the study. 


\subsection{Data analysis}

The data were content-analysed using an iterative and recursive process (Miles \& Huberman, 1994) to reduce it to more relevant and manageable information units (Weber, 1990). This was done by reading and rereading the transcripts in order to become familiar with the data.

\subsection{Reliability and trustworthiness}

According to Patton (2002) the researcher is the instrument for data collection and analysis in qualitative research, therefore, his/her experience is important for the credibility of the data. The primary author, having extensive background experience in coaching golf, and good contextual knowledge about the sport and terminology associated with the sport, conducted all interviews. This also helped to build rapport with the participants (Eklund, 1993).

The credibility of the findings of the study was established in the following ways, first, the responses of the participants were recorded and transcribed verbatim, secondly the data were analysed independently by both researchers, and thirdly, an independent researcher examined the findings in conjunction with the recordings and transcripts.

\section{Results and Discussion}

All participants were positively inclined towards the use of video analysis in golf coaching. In terms of their usage of video analysis, all participants in the study used video analysis in at least five out of seven coaching sessions.

\subsection{Positive experiences}

Analysis of the data revealed that the positive aspects associated with using video analysis outnumbered the negative aspects. Participants in the study indicated that video analysis enabled them to respond more swiftly to areas of weaknesses of golf players. This finding echoes Magowen's (2014) assertion that feedback from video analysis enables the golfer to make quicker changes to his/her technique. It also facilitates the gaining of a clearer understanding of stroke/swing and movement patterns, and draws comparisons with professional players and players of similar ability. According to Magowen (2014), coaches are also able to pinpoint faults more quickly and take appropriate measures to correct faults associated with the sport. Participants also perceived that players have a better and quicker understanding of their golf swing and posture, and what measures were needed to improve; this is because they could see themselves on video. One of the most pronounced positive aspects, according to the participants, was that they were able to identify minor details in a player's technique. The benefits of video golf swing analysis alone are huge and improve a coach's teaching ability. The ability to put precise angle measurements to spine, arm flex, and general posture positions eliminates the guesswork from coaching, and contributes greatly to improved playing styles (Anon, 2008).

\subsection{Negative experiences}

Although the participants reported fewer negative aspects, it is important to take note of them. A significant negative aspect, according to the participants, was that the inclusion of video technology in their coaching resulted in a tendency to deviate from their normal style of coaching, and adopt a very technical approach to coaching. Instead of being natural in their coaching, they tended to be over reliant on the technology, and sound pedagogical principles of coaching are ignored. This sometimes has an influence on their athletes, who tend to lose the natural approach to playing golf, get confused with too much information at their disposal, and begin to doubt their own ability because of their faults being exposed through this technique. Another important negative experience mentioned by participants was the athletes' desire to emulate other players. Previous research on video analysis (Rothstein, 1976) suggested that video analysis could be an ineffective means of presenting knowledge of performance.

\subsection{Player development}

Participants expressed that video analysis contributed greatly to player development. Players could now rely on both their coaches as well as video analysis, which could be viewed both during and outside practice sessions. Outside official practice sessions, video analysis assisted players to improve and master techniques in the absence of the coach. Cole 
(2009) posits that video analysis provides tremendous feedback to an athlete. If they are able to see their own movements through video analysis, they may be able to understand and correct their own mistakes more quickly. It also helps them to develop more confidence in their coaches. According to Brian Whitcomb, the President of the American PGA, the V1 Pro provides golfers with the opportunity to elevate their skills and grow the game of golf (Interactive Frontiers Inc., 2007).

\subsection{Barriers and constraints to using video analysis}

With regard to the barriers and constraints associated with the use of video analysis in golf coaching, participants indicated that poor weather conditions often hindered the use of video technology. Although most participants indicated that, they had alternate plans if the weather was bad, poor weather conditions often interrupted their planning and scheduling. Participants indicated that it was important to have adequate sunlight so that clear video footage could be obtained. They were also of the opinion that cameras should have the correct shutter speed to capture the key elements of the movements in golf. An important factor that played a role in the type of equipment used in video analysis was the cost. While all participants indicated that they invested in the technology, a few of them were still struggling to recoup their investment.

Participants also expressed that they needed training in handling equipment as they often had to move around with equipment and they sometimes cannot keep still, especially when they use the Ipad. Power outages were also identified as a barrier to using video analysis. Most of the participants indicated that they were unable to keep pace with rapid improvements in the technology to which new software was always being introduced.

\subsection{Focus of video analysis}

Participants in the study were requested to indicate what they mainly focused on in video analysis. Among the different areas of focus were improved timing, better ball strike, improved handicaps, good swing under pressure, better impact, better biomechanics and better swings. Bertram, Marteniuk and Guadagnoli (2008) found that video feedback provided important information for players to improve their timing. In addition, the authors reported that although no significant changes were observed regarding their sample's swings, subtle changes were noticed. In terms of specific skills, all participants indicated that posture and stance, ball position, grip, aim and alignment, laws and principles of swing, and takeaway path were other areas that participants focused on. Previous research (Guadagnolis, Holcomb \& Davis, 2002) found that by video feedback focussing on specific aspects of the game, those aspects (inter alia accuracy and distance) improved.

\subsection{Supplementary equipment}

While all participants were happy with the V1 Pro technology that they were currently using, they were not averse to supplementary equipment that they would use in addition to video analysis. These included alignment sticks (to guide swing, aim and alignment) and a trackman, which could be used to monitor the club head speed, angle of approach, impact position and ball flight. 3D analysis programmes was also supplementary equipment they preferred to use. This equipment requires a player to wear a jacket, which portrays him/her in 3D. It can be manipulated to view the players' swing and stance from various angles.

\section{Strengths, Limitations and Implications for Further Research}

The strength of the current study lies in its purposive sample (Sooful et al., 2010), which ensured that data was collected from participants who were experienced in the use of video analysis in golf coaching.

A notable limitation of the study was the small sample size of eight participants. This makes the generalisability of the findings to the greater population of golf coaches questionable. The findings of the study, however, do provide valuable perspectives on the use of video analysis in golf coaching, which can be used as a foundation for other studies. Future studies should adopt a quantitative research approach to investigate the differences in player skills by using samples, from those who are coached using video analysis, and those who are coached using traditional coaching methods. 


\section{Conclusion}

The purpose of the study was to gain an insider perspective of video analysis in golf coaching. The findings indicate that the use of video analysis is popular among professional golf coaches. Given the many positive aspects associated with using video analysis in golf coaching, and the fact that coaches continuously strive to get the best performance from their athletes, the use of video analysis in golf coaching appears to be a positive step towards achieving this goal.

\section{References}

Anon (2008). Golf swing analysis. [Online] Available: http://www.golf-swing-analysis.com/

Rothstein, A. (1976). Feedback: knowledge of performance. . [Online] Available: http://scienceofsportsperformance.wordpress. com/2013/03/19/feedback-knowledge-of-performance/. Date of access: 2014/05/23.

Bertram, C. P., Marteniuk, R. G., \& Guadagnolis, M. A. (2008). On the use and misuse of video analysis. Annual Review of Golf Coaching. 1, 37-46.

Cole, S. (2009). The benefits of video analysis in golf instruction. . [Online] Available: http://www.articlesnatch.com/Article/The-BenefitsOf-Video-Analysis-In-Golf-Instruction/825028. Date of access: 2014/05/23.

Cromack, C. (2011). Target oriented golf \& the evolution of golf instruction. [Online] Available: http://golfstateofmind.com/target-orientedgolf-the-evolution-of-golf-instruction/

Dane, F. (1990). Research methods. Pacific Grove: Brooks/Cole.

Eklund, R. C. (1993). Considerations for gaining entry to conduct sport psychology field research. The Sport Psychologist, 7, 232-243.

Guadagnoli, M., Holcomb, W., \& Davis, M. (2002). The efficacy of video feedback for learning the golf swing. Journal of Sport Sciences, 20(8), 615-622.

Harmon, B. (2014). Learn swing secrets at the Butch Harmon School of Golf. [Online] Available: www.butchharmon.com. Date of access: $2014 / 04 / 20$

Interactive Frontiers Inc. (2007). V1 pro partners with play golf America during 89th PGA championship at Southern Hills. [Online] Available: http://www.v1golf.com/press/20070806.asp. Date of access: 2014/05/23.

Johnson, H. (2011). Where your swing hurts. How to avoid 5 common golf injuries. [Online] Available: www.golfdigest.com. Date of access: $2014 / 05 / 23$

Lane, J.M. (2007). History of golf instruction. [Online] Available: http://www.usgtf.com/historyinstruction3.html. Date of access: 2014/04/21.

Magowen, M. (2014). Benefits of video analysis. [Online] Available: http://golfesquire.com/Video.aspx. Date of access: 2014/04/20.

McCarron, J. (2013). What are the benefits of video analysis in sports? [Online] Available: http://www.livestrong.com/article/525371what-are-the-benefits-of-video-analysis-in-sports/. Date of access: 2014/05/23.

Mclean, J. (2014). Jim McLean golf schools. [Online] Available: http://jimmclean.com/texas/Facility/About/tabid/126/Default.aspx. Date of access: 2014/05/23.

Miles, M. B., \& Huberman, A. M. (1994). Qualitative data analysis (2nd ed.). Thousand Oaks, CA: Sage.

Patton, M. (2002). Qualitative research \& evaluation methods (3rd ed.). Thousand Oaks, CA: Sage.

Sooful, A., Surujlal, J., \& Dhurup, M. (2010). Dance and music as mediums for the social integration of children with intellectual disabilities into mainstream society. African Journal for Physical Health Education, Recreation and Dance, 16(4), 681-697

Weber, R. P. (1990). Basic content analysis. Newbury Park, CA: Sage.

Wikipedia (2014). Video motion analysis. [Online] Available: http://en.wikipedia.org/wiki/Video_motion_analysis. Date of access: $2014 / 05 / 23$

Van Staden, S. (2014). Closing the gap between technology, training. Saturday Citizen, 15 March, p41. 